\title{
Participação de meninas no Fútbol Callejero: intervenção na Educação Física Escolar
}

\author{
Girls Participation in Fútbol Callejero: intervention in School Physical Education
}

Participación de Niñas en el Fútbol Callejero: intervención en Educación Física Escolar

\author{
Maria Carolina Derencio Oliveira ${ }^{1}$; Tiago Grifoni ${ }^{2}$; NATHan RAPHAEL VARotTo ${ }^{3}$ \\ Universidade Federal de São Carlos, UFSCAR, São Carlos-SP, BraSil
}

\begin{abstract}
RESUMO
Este artigo expõe o percurso investigativo de uma unidade didática, embasada no Fútbol Callejero, aplicada em uma turma de $9^{\circ}$ ano, cujo objetivo foi analisar, compreender e descrever a participação de meninas na prática do Fútbol Callejero durante aulas de Educação Física Escolar. O estudo foi conduzido com abordagem qualitativa descritiva, sendo observadas 6 aulas de Educação Física. Foram elaborados 6 diários de campo e a análise do conteúdo foi realizada via fenomenologia, na modalidade fenômeno situado. Três categorias emergiram: A) "Se ia ser melhor ficar olhando o jogo, prestando atenção em tudo, ou jogar"; B) "No outro jogo eu saí com a bola, agora começa você"; C) "Mas se eu pedir pra parar, tem que parar, entendeu?". Os resultados apontaram que as meninas assumiram funções determinantes no desenvolvimento da prática do Fútbol Callejero, mostrando solidariedade e sororidade; todavia, ainda se observou algumas reduções na participação das meninas.
\end{abstract}

Palavras-chave: Fútbol Callejero. Gênero. Educação Física Escolar.

\begin{abstract}
This article exposes the investigative course of a didactic unit, based on Fútbol Callejero, applied in a 9th grade group, whose aim was to analyze, understand and describe the participation of girls in the practice of Fútbol Callejero during Physical Education classes at school. The study was conducted with a qualitative descriptive approach, and 6 Physical Education classes observed. Six sets of field notes were developed, and the content analysis was conducted via phenomenology, in the situated phenomenon mode. Three categories emerged from the nomothetic matrix: A) "If it would be better to watch the game, paying attention to everything, or to play"; B) "Last match I started with the ball, now you start"; C) "But if I ask you to stop, you have to stop, did you understand?". The results showed that the girls assumed decisive roles in the development of the practice of Fútbol Callejero, showing solidarity and sorority; however, there was still some reduction in girls' participation.
\end{abstract} Keywords: Fútbol Callejero. Genre. School Physical Education.

\section{RESUMEN}

Este artículo expone el camino de investigación de una unidad didáctica, basada en el Fútbol Callejero, aplicada a un grupo del noveno año, objetivando analizar, comprender y describir la participación de las niñas en la práctica del Fútbol Callejero durante las clases de Educación Física Escolar. El estudio se realizó con un enfoque descriptivo cualitativo, con 6 clases de educación física miradas. Se prepararon seis diarios de campo y el análisis del contenido se realizó por fenomenología, en el modo de fenómeno situado. De la matriz nomotética surgieron tres categorías: A) "Si resultaría mejor estar mirando el partido, prestar atención, o jugar"; B) "El partido anterior empecé yo, ahora empiezas"; C) "Pero si te pido para parar, tienes que parar, ¿entiéndelo?”. Los resultados mostraron que las niñas asumieron roles decisivos en el desarrollo de la práctica del Fútbol Callejero, demostrando solidaridad y sororidad; sin embargo, hubo algunas reducciones en la participación de las niñas.

Palabras clave: Fútbol Callejero. Género. Educación Física Escolar.

\footnotetext{
${ }^{1}$ Graduanda em Licenciatura em Educação Física pela UFSCar. E-mail: m.carolderencio@ gmail.com. ORCID: http://orcid.org/0000-0002-7816-7412.

2 Mestrando em Educação Física pelo PROEF/UFSCar. E-mail: tiago.grifoni@hotmail.com. ORCID: http://orcid.org/0000-0002-8429-3802.

${ }^{3}$ Doutorando em Educação pela UFSCar. E-mail: varotton@gmail.com. ORCID: http://orcid.org/0000-00026722-9083.
}

Motricidades: Rev. SPQMH, v. 4, n. 1, p. 15-26, jan.-abr. 2020 | ISSN 2594-6463 |

DOI: http://dx.doi.org/10.29181/2594-6463.2020.v4.n1.p15-26 


\title{
INTRODUÇÃOO
}

Atribui-se a origem das práticas do Fútbol Callejero ${ }^{4}$ em meados de 1994, às imediações de um bairro empobrecido chamado Moreno, em Buenos Aires, na Argentina (ROSSINI et al., 2012; VAROTTO et al., 2018). Inicialmente, suas vivências eram realizadas por classes populares, com enfoque aos "[...] jovens moradores de periferias urbanas empobrecidas" (VAROTTO et al., 2018, p. 105), uma vez que, por intermédio do Fútbol Callejero, busca-se a recuperação do "[...] espaço de protagonismo e diálogo entre os jovens, em um contexto onde a violência estrutural atravessava todas as relações: familiares, no bairro, a escola e com a comunidade" (VAROTTO et al., 2018, p. 106).

Desse modo, sua proposta crítica ganhou destaque entre educadores que começaram a difundir a cultura do Fútbol Callejero como um espaço social de educação e cidadania (SILVA GUTIERREZ; DOTTO; ALLET, 2016). Essa associação do esporte com o lazer adquiriu tamanhas proporções que, atualmente, tem-se:

[...] o Movimento Fútbol Callejero como um instrumento de mobilização e organização da juventude. A ideia fundamental é voltar às raízes do futebol de rua, uma prática desportiva de lazer autorregulada, onde regras são previamente acordadas e tacitamente respeitadas por todos os participantes de um jogo, sem a necessidade de uma regulação ou autoridade externa (SILVA GUTIERREZ; DOTTO; ALLET, 2016, p. 20).

Com início na América Latina, esse movimento é formado, até o momento, por um conjunto de 14 organizações sociais das Américas do Sul e Central (MOVIMIENTO, 2020). O Movimento Fútbol Callejero compartilha a missão, a partir da metodologia característica do Fútbol Callejero, de "[...] construir cidadania, defender os direitos humanos, lutar pela justiça, promover uma sociedade inclusiva e reconhecer a diversidade cultural e étnico-racial" (MOVIMIENTO, 2013, s.p.).

Alguns autores, como Rossini et al. (2012), conforme citado por Varotto, Gonçalves Junior e Lemos (2017), destacam que:

\begin{abstract}
A metodologia do "Fútbol Callejero" propõe regras que o torna diferente do futebol convencional: meninas e meninos jogam juntos, não participam árbitros/as e as partidas se dividem em três tempos. No primeiro tempo, as equipes estabelecem as regras do jogo em conjunto e de maneira consensual, no segundo tempo se joga a partida e no terceiro tempo, todos/as os/as jogadores/as dialogam sobre o desenvolvimento do jogo e se houve respeito às regras acordadas mutuamente (p. 93).
\end{abstract}

Desse modo, a partir das regras estabelecidas no primeiro tempo, como também a partir das pontuações a elas atribuídas, torna-se vitoriosa a equipe que mais pontuar nesses acordos (VAROTTO; GONÇALVES JUNIOR; LEMOS, 2017). Por consequência, o ato de marcar gol "[...] deixa de ser a principal ferramenta para a vitória e com isso o jogo se dá e se faz valer [...] pelos três pilares do Fútbol Callejero: cooperação, respeito e solidariedade" (VAROTTO et al., 2018, p. 107).

No "Fútbol Callejero" há no terceiro tempo diálogo entre todos/as os/as envolvidos/as acerca dos acontecimentos no jogo, que vão desde o

\footnotetext{
${ }^{4}$ A expressão Fútbol Callejero é originária da língua espanhola que, em português, pode-se traduzir para "Futebol de Rua" ou "Futebol Rueiro". Todavia, ao longo do texto, a expressão será mantida em espanhol, a fim de assegurar a essência e originalidade da expressão originária da Argentina.
} 
estabelecimento da pontuação final (conforme combinados feitos no primeiro tempo), até a reflexão da efetivação dos anteriormente citados três pilares. Trata-se, portanto, o "Fútbol Callejero" de uma ferramenta educativa, pois a partir das particularidades desta prática podemos utilizá-la na "transformação" dos/as envolvidos/as de maneira dialógica, sem impor nada a ninguém e sim respeitando a cada um/a que se lança a esse processo dialógico (VAROTTO; GONÇALVES JUNIOR; LEMOS, 2017, p. 94).

O Fútbol Callejero, além de ser sustentado por seus três pilares, também conta com um/a mediador/a, que atua a fim de facilitar o diálogo e a interação entre as equipes (VAROTTO; GONÇALVES JUNIOR; LEMOS, 2017). A mediação permeia esses três tempos, proporcionando uma reflexão coletiva, resolvendo conflitos por meio do diálogo, incentivando a participação de todos/as os/as participantes (ROSSINI et al., 2012; VAROTTO et al., 2018).

Como todos/as possuem o direito de expor suas expectativas, Souza Júnior, Martins e Belmonte (2015) afirmam que isso contribui para condutas coletivas e aceitação de diferenças. Entretanto, um recente estudo de Varotto, Gonçalves Junior e Lemos (2017) identificou em seus resultados, de maneira expressiva, a presença da relação de gênero entre meninos e meninas, na faixa etária de 7 a 17 anos: "Empadinha pediu a fala e disse: 'Eu acho que meu time não merece o ponto de cooperação, pois o Messi e o Flash não passavam a bola para as outras pessoas'. Flash disse: 'Ah, meu time tinha mais meninas aí é ruim"” (VAROTTO; GONÇALVES JUNIOR; LEMOS, 2017, p. 98).

Ainda, nesse mesmo estudo: "Frynkin e Rafaelzinho não passavam a bola para Fiorella e inicialmente David Luiz estava no gol e a todo o momento tentava jogar a bola para ela, mas os outros dois meninos não deixavam a bola chegar nela" (VAROTTO; GONÇALVES JUNIOR; LEMOS, 2017, p. 98).

Nesses trechos destacados, percebe-se que houve uma resistência em incluir as meninas durante a prática do Fútbol Callejero, pois alguns meninos impossibilitaram que as mesmas participassem do jogo. Mesmo com os autores informando que, ao longo do processo, "[...] os/as envolvidos/as conseguiram perceber a situação e atuar de modo respeitoso, solidário e cooperativo" (VAROTTO; GONÇALVES JUNIOR; LEMOS, 2017, p. 98), é possível perceber que no jogo ocorreu um distanciamento dos três pilares fundamentais do Fútbol Callejero. Além disso, Varotto, Gonçalves Junior e Lemos (2017) não buscaram compreender a percepção dessas meninas sobre esse fato.

Logo, essa observação expõe que ainda há lacunas na literatura a serem preenchidas, como também analisadas e descritas sobre a relação de gênero intrínseca na prática do Fútbol Callejero que reflete uma temática social cada vez mais emergente.

\section{Procedimentos Metodológicos}

Este estudo foi realizado a partir da abordagem qualitativa, do tipo descritiva, com delineamento fenomenológico e mantendo o seu sentido ético pelo caráter humanístico, inter-relacional e empático (MINAYO; GUERRIERO, 2014). Deste modo, considerouse que todos os dados da realidade são importantes e devem ser examinados (GODOY, 1995) através de um "[...] rigoroso olhar metodológico a respeito do real" (CAPPI, 2001, p. 8).

O interesse [...] está em verificar como determinado fenômeno se manifesta nas atividades, procedimentos e interações diárias. Não é possível compreender o comportamento humano sem a compreensão do quadro 
referencial (estrutura) dentro do qual os indivíduos interpretam seus pensamentos, sentimentos e ações (GODOY, 1995, p. 63).

Em busca de analisar, compreender e descrever a participação de meninas na prática do Fútbol Callejero durante aulas de Educação Física Escolar, realizou-se uma inserção em uma escola da rede pública do munícipio de Araraquara, no interior do estado de São Paulo, por intermédio do professor responsável pela disciplina de Educação Física, em comum acordo com a diretoria da instituição e os/as demais funcionários/as.

A inserção ocorreu de março a maio de 2019, e a escolha dos participantes para este estudo deu-se mediante uma reunião entre o professor de Educação Física com os demais professores/as da instituição, que selecionaram a turma que mais apresentava conflitos de convivência entre os/as próprios/as alunos/as.

Deste modo, a turma escolhida foi o $9^{\circ}$ ano $\mathrm{B}$ do ensino fundamental, e os/as participantes e respectivos/as responsáveis foram convidados/as e informados/as sobre a pesquisa e os procedimentos envolvidos. Também foram fornecidas informações sobre o sigilo dos dados e a preservação das identidades dos/as alunos/as, que, por sua vez, escolheram nomes fictícios para o estudo. Assim, participaram do estudo 36 estudantes que concordaram em participar da pesquisa, por livre aceitação, assinando o Termo de Assentimento Livre e Esclarecido (TALE) e o Termo de Consentimento Livre e Esclarecido (TCLE), respectivamente.

Então, o professor de Educação Física elaborou uma unidade didática (quadro 1), considerando temas e objetivos que se correlacionam com a prática do Fútbol Callejero. Essa unidade didática foi formulada para um total de 8 aulas, das quais foram acompanhadas e observadas $6^{5}$ delas, com duração de 100 minutos cada.

Quadro 1: Unidade didática desenvolvida no estudo.

\begin{tabular}{|c|c|c|}
\hline & Temas & Objetivos \\
\hline Aula 1 & $\begin{array}{l}\text { - Diagnóstico do futebol que a } \\
\text { turma pratica e conhece; } \\
\text { - Apresentação da pesquisa. }\end{array}$ & $\begin{array}{l}\text { - Vivenciar o futebol de forma autônoma e refletir } \\
\text { sobre o futebol praticado e conhecido pela turma; } \\
\text { - Compreender a proposta da pesquisa a ser } \\
\text { desenvolvida nas aulas. }\end{array}$ \\
\hline Aula 2 & $\begin{array}{l}\text { - Fútbol Callejero: origem, } \\
\text { fundamentos e os } 3 \text { pilares. }\end{array}$ & $\begin{array}{l}\text { - Vivenciar e compreender a metodologia } \\
\text { Callejera. }\end{array}$ \\
\hline Aula 3 & - Árbitro/a x Mediador/a. & $\begin{array}{l}\text { - Identificar as funções do/a árbitro/a em uma } \\
\text { partida de futebol; } \\
\text { - Capacitar os/as alunos/as para atuarem como } \\
\text { mediadores/as na prática do Fútbol Callejero. }\end{array}$ \\
\hline Aula 4 & - Gênero nos esportes. & $\begin{array}{l}\text { - Identificar como se dá as relações de gênero no } \\
\text { universo esportivo: atividade júri simulado. }\end{array}$ \\
\hline Aula 5 & - Protagonismo Juvenil. & $\begin{array}{l}\text { - Conscientizar os/as alunos/as sobre a importância } \\
\text { de lutarem por seus direitos. }\end{array}$ \\
\hline Aulas 6 e 7 & $\begin{array}{l}\text { - Festival interno de Fútbol } \\
\text { Callejero. }\end{array}$ & $\begin{array}{l}\text { - Organizar um torneio da sala de Fútbol Callejero, } \\
\text { com a mediação realizada pelos/as alunos/as; } \\
\text { - Identificar as fases de organização do evento e } \\
\text { montagem da tabela. }\end{array}$ \\
\hline Aula 8 & $\begin{array}{l}\text { - Agradecer e celebrar os } \\
\text { momentos compartilhados. }\end{array}$ & $\begin{array}{l}\text { - Concluir a intervenção; } \\
\text { - Refletir sobre outra possibilidade de praticar o } \\
\text { Futebol na escola. }\end{array}$ \\
\hline
\end{tabular}

Fonte: Elaboração própria.

\footnotetext{
${ }^{5}$ As aulas acompanhadas e observadas para este estudo foram as de 1 a 6 da unidade didática.
} 
Como método de coleta de dados, utilizou-se o diário de campo porque consiste em um "[...] relato escrito daquilo que o investigador ouve, vê, experiencia e pensa no decurso da recolha e refletindo sobre os dados de um estudo qualitativo" (BOGDAN; BIKLEN, 1994, p.150). Vale ressaltar que os diários de campo foram construídos descrevendo sistematicamente as relações entre o educador e educandos/as, bem como entre os/as próprios/as alunos/as.

Todo o conteúdo resultante foi analisado a partir dos preceitos da fenomenologia, uma ciência aplicada aos "[...] estudos dos fenômenos: dos objetos, dos eventos e dos fatos da realidade" (PETRELLI, 2001, p. 15). Os diários foram analisados, especificamente, com a modalidade fenômeno situado, na qual:

[...] o pesquisador não necessita de pressupostos ou pré-concepções da natureza do fenômeno investigado, como nas Ciências Naturais. Apenas fazse necessário buscar as descrições das experiências dos sujeitos envolvidos para que se possa mostrar a essência deste fenômeno diante dos olhos dos leitores, ou seja, para que o leitor possa compreender como estão vivendo e que experiência estão passando em uma determinada situação de vida (MORENO; JORGE; GARCIA, 2004, p. 350).

As análises foram realizadas via propostas de Giorgi $(1985)^{6}$, conforme citado por Andrade e Holanda (2010), seguindo as quatro etapas descritas a seguir.

Etapa 1 - Leitura: todas as descrições dos diários de campo foram lidas, a fim de se alcançar o sentido geral do todo;

Etapa 2 - Releitura: todas as anotações foram relidas, quantas vezes julgou-se necessário, e nelas foram identificadas unidades significativas que ressaltaram o fenômeno pesquisado;

Etapa 3 - Expressão do Sentido Psicológico: com as unidades significativas delineadas e através da linguagem de senso comum, foram determinadas categorias temáticas que, posteriormente, foram organizadas em uma matriz nomotética (quadro 2), realizando um "[...] movimento em direção à generalidade" (MARTINS; BICUDO, 2005, p. 106), que compreendeu as proposições individuais, convergências e divergências (MARTINS; BICUDO, 2005).

Etapa 4 - Sintese das Unidades Significativas: foi realizada uma síntese das unidades significativas do fenômeno, produzindo assim uma estrutura da experiência. Nessa síntese, foram reagrupados "[...] os constitutivos relevantes para chegar a uma análise da estrutura fenômeno" (ANDRADE; HOLANDA, 2010, p. 267), assim, essa estrutura da experiência assumiu um "[...] propósito de confirmação ou de crítica" (ANDRADE; HOLANDA, 2010, p. 267).

\section{DISCUSSÃO DOS RESULTADOS}

Os resultados foram organizados concomitantemente à construção da matriz nomotética (quadro 2), a qual possibilitou uma melhor visualização das convergências e divergências destacadas para análise, compreensão e descrição da participação de meninas na prática do Fútbol Callejero durante aulas de Educação Física Escolar. Sendo assim, as categorias emergentes foram: A) "Se ia ser melhor ficar olhando o jogo, prestando atenção em tudo, ou jogar"; B) "No outro jogo eu saí com a bola, agora começa você"; C) "Mas se eu pedir pra parar, tem que parar, entendeu?".

6 GIORGI, A. Sketch of a psychological phenomenological method. In: A. Giorgi (Org.). Phenomenology and psychological research. Pittsburg: Duquesne University Press, 1985. p. 8-22. 
QUADRO 2: Matriz Nomotética ${ }^{7}$.

\begin{tabular}{|c|c|c|c|c|c|c|}
\hline$\overbrace{\text { Categorias }}^{\text {Diários }}$ & $\underset{15 / 03}{\text { I }}$ & $\begin{array}{c}\text { II } \\
\text { Aula } 2 \\
22 / 03\end{array}$ & $\begin{array}{c}\text { III } \\
\text { Aula } 3 \\
29 / 03\end{array}$ & $\begin{array}{c}\text { IV } \\
\text { Aula } 4 \\
05 / 04 \\
\end{array}$ & $\begin{array}{c}\text { V } \\
\text { Aula } 5 \\
26 / 04 \\
\end{array}$ & $\begin{array}{c}\text { VI } \\
\text { Aula 6 } \\
03 / 05 \\
\end{array}$ \\
\hline $\begin{array}{l}\text { A) "Se ia ser melhor } \\
\text { ficar olhando o jogo, } \\
\text { prestando atenção } \\
\text { em tudo, ou jogar" }\end{array}$ & $\begin{array}{l}1,2,3,6 \\
9,10,11 \\
15,18\end{array}$ & $\begin{array}{c}1,2,3,5 \\
\quad 6,7\end{array}$ & $\begin{array}{c}2,4,6,7, \\
8,9,10, \\
11,14 \mathrm{~d}, \\
15 \mathrm{~d}, 18, \\
19,24, \\
32,33\end{array}$ & $\begin{array}{ll}1,2, & 3,5, \\
8,10, & 12, \\
13, & 14, \\
17, & 18, \\
19, & 20, \\
22, & 23, \\
31, & 32, \\
34 d, & 36, \\
37 d, & 38, \\
39,41 & \end{array}$ & $\begin{array}{c}2,4,5,6 \\
7,8,9 \\
18,19 \\
20,23 \mathrm{~d} \\
24,25\end{array}$ & $\begin{array}{c}1,2,3,5 \\
7,8,9 \\
10,12 \mathrm{~d}, \\
13 \mathrm{~d}, 14 \mathrm{~d}, \\
22,23 \mathrm{~d}, \\
24,25, \\
26 \mathrm{~d}, 27, \\
31,33 \mathrm{~d}, \\
34,35, \\
36,37\end{array}$ \\
\hline $\begin{array}{l}\text { B) "No outro jogo } \\
\text { eu saí com a bola, } \\
\text { agora começa você" }\end{array}$ & $\begin{array}{c}7,12,13 \\
14,16 \\
20,21\end{array}$ & 9,11 & $\begin{array}{l}1,5,12 \\
16,20 \\
27,30\end{array}$ & $\begin{array}{c}6,7,15 \\
16,27 \\
40 \mathrm{~d}\end{array}$ & $\begin{array}{c}1,3,16 \\
17,22\end{array}$ & $\begin{array}{c}4,6,11, \\
21,29, \\
30,32,39\end{array}$ \\
\hline $\begin{array}{l}\text { C) "Mas se eu pedir } \\
\text { pra parar, tem que } \\
\text { parar, entendeu?" }\end{array}$ & $\begin{array}{l}4 \mathrm{~d}, 5 \mathrm{~d}, 8 \\
17,19,22\end{array}$ & $4,8,10$ & $\begin{array}{c}3,13,17, \\
21,22, \\
23,25, \\
26,28, \\
29,31\end{array}$ & $\begin{array}{c}4,9 \mathrm{~d}, 11, \\
21,24, \\
25,26, \\
28,29, \\
30,33,35\end{array}$ & $\begin{array}{l}10 \mathrm{~d}, 11 \mathrm{~d}, \\
12 \mathrm{~d}, 13 \\
14 \mathrm{~d}, 15 \mathrm{~d}, \\
21\end{array}$ & $\begin{array}{c}15,16 \\
17,18 \mathrm{~d} \\
19,20 \\
28,38\end{array}$ \\
\hline
\end{tabular}

Fonte: Elaboração própria.

\section{A) "SE IA SER MELHOR FICAR OLHANDO O JOGO, PRESTANDO ATENÇÃO EM TUDO, OU JOGAR"}

Esta categoria emergiu dos aspectos observados e relatados acerca das participações das meninas nas aulas de Educação Física Escolar acompanhadas. Como o Fútbol Callejero permite outras possibilidades de se envolver com sua prática, o nome dessa categoria se deu a partir da fala de uma aluna que expressou essas possibilidades: "Ah, porque, da última vez que eu joguei, eu não gostei muito. E agora eu quis ser mediadora para ver como que ia ser. Se ia ser melhor ficar olhando o jogo, prestando atenção em tudo, ou jogar" (IV - 39) ${ }^{8}$.

A prática do Fútbol Callejero possibilita uma interação mais igualitária entre os(as) participantes, uma vez que a construção do jogo é coletiva e as equipes são formadas por meninos e meninas (VAROTTO et al., 2018). Desse modo, como a metodologia do Fútbol Callejero proporciona um "[...] grande potencial para o empoderamento das mulheres" (BELMONTE; GONÇALVES JUNIOR; SOUZA JÚNIOR, 2018, p. 257), nota-se que as meninas, assumem funções determinantes para o desenvolvimento da prática, como: "A segunda regra foi indicada pela aluna Mari" (III 02); "Já a quarta regra foi falada pela aluna Fer" (III - 04); "Na quadra, a aluna Mari chamou o aluno Biro-Biro para fazerem a divisão dos times" (IV - 03).

Vale salientar que a melhor inserção da mulher nos esportes, com enfoque para "[...] modalidades esportivas equivocadamente compreendidas como masculinas" (BELMONTE; GONÇALVES JUNIOR; SOUZA JÚNIOR, 2018, p. 257), como é o caso do futebol, foi marcante neste ano de 2019. No Brasil, pela primeira vez, três grandes eventos de futebol de mulheres foram transmitidos em redes nacionais abertas

\footnotetext{
${ }^{7}$ Categorias e suas respectivas unidades significativas, em algarismos arábicos. Na coluna à esquerda foram colocadas as categorias provenientes dos registros dos diários de campo; na linha superior foram indicados os números dos diários de campo, em algarismos romanos; "d": divergências encontradas, quando comparadas à generalidade das demais unidades significativas.

${ }^{8}$ Diário número IV e Unidade Significativa número 39.
} 
de televisão: Copa do Mundo de Futebol Feminino, Campeonato Brasileiro de Futebol Feminino e Copa Libertadores da América de Futebol Feminino.

O aumento na divulgação desses três eventos em todo o país reitera a participação de mulheres no ambiente esportivo, assim como foi observado nas aulas de Educação Física Escolar, pautadas nos três tempos do Fútbol Callejero: "No jogo 2, foi uma menina que fez o primeiro chute" (I - 10); "A sexta e última regra foi proposta pelas alunas Mari e Lu" (III - 06);

Logo após, o prof. Tiago fez um questionamento para a aluna Mili:

Prof. Tiago: "Então você acha que o outro time não merece o ponto de respeito?"

E a aluna Mili respondeu:

Aluna Mili: "Respeito merece, tiveram respeito".

O prof. Tiago interrompeu a fala da aluna, para refazer a pergunta:

Prof. Tiago: "Não, respeito às regras".

E a aluna Mili respondeu novamente:

Aluna Mili: “Às regras, não” (IV - 36).

Como dito anteriormente, as alunas realmente assumiram funções determinantes nessas aulas de Educação Física e a mediação não foi uma exceção. Vista como um "[...] espaço que permeia os três tempos da metodologia do Fútbol Callejero e não simplesmente terceiro tempo" (VAROTTO et al., 2018, p. 107), “[...] as alunas Jana, Rafaela, Teltel e Leticia se dispuseram para fazer as mediações do dia" (VI - 07).

Assim como descrito por Varotto et al. (2018), assumir a função de mediador/a promove "[...] o encontro das consciências e a possibilidade da compreensão das situações pelo diálogo" (p. 119), o qual foi desenvolvido pelas meninas na mediação:

A mediadora Gabizela chamou a atenção da turma e disse:

Aluna Gabizela: "A regra da dança tá ou não?".

A maior parte da turma respondeu "tá". Entretanto, para confirmar a primeira regra, a mediadora Jana questionou os/as alunos/as:

Aluna Jana: "Todo mundo concorda?".

E a resposta "sim" foi dita em coro (IV - 05).

Como também relatado pelas próprias alunas:

Prof. Tiago: "O que vocês acharam de ser mediadora?"

A primeira mediadora a se manifestar foi a aluna Jana:

Aluna Jana: "Ah, eu gostei".

Prof. Tiago: "Por quê?".

Aluna Jana: "Porque quando a gente é mediadora, a gente tipo, olha o jogo, presta mais atenção, e percebe mais".

A mediadora Giba também falou na sequência:

Aluna Giba: "É, tipo, fica mais atento".

E a mediadora Jana completou:

Aluna Jana: "Repara mais detalhes" (IV - 38).

Essa categoria permite a reflexão de que houve um aumento na participação das meninas nas aulas de Educação Física Escolar, visto que as alunas puderam reconhecer seus espaços na prática regida pelos preceitos do Fútbol Callejero.

\section{B) "NO OUTRO JOGO EU SAÍ COM A BOLA, AGORA COMEÇA VOCÊ"}

Esta categoria foi formada a partir das relações manifestadas apenas entre as meninas. Para isso, nomeou-se essa categoria a partir da fala de uma aluna que 
demonstra uma relação afetiva entre duas meninas: "[...] a aluna Mari chamou a aluna Lu e disse para ela: no outro jogo eu que saí com a bola, agora começa você" (II - 11).

Uma das diversas formas de dominação masculina consiste na "[...] ideia de que a mulher não pode possuir e nem consegue ter uma relação de afetividade, empatia e amizade com outra mulher" (SILVA, 2016, p. 13). Todavia, essa categoria vem demonstrar exatamente o contrário, pois houve momentos de solidariedade e sororidade feminina, como o da seguinte unidade significativa: “[...] o prof. Tiago questionou-a acerca dos motivos de sua sugestão, e essa aluna respondeu que era apenas para que as meninas tivessem mais chances de defesas, uma vez que não estão acostumadas a jogarem no gol" (III - 05).

Essa tal sororidade feminina expressa a: "[...] união e aliança entre as mulheres, baseadas na empatia e companheirismo, em busca de alcançar objetivos comum" (SOUZA, 2016, p. 41) e, mesmo que inconscientemente, a maioria das alunas do $9^{\circ}$ ano em questão já possuem a sororidade em suas atitudes, diálogos e resolução de conflitos:

E a aluna Mili tomou a palavra, dizendo:

Aluna Mili: "Teve gente que pediu pra parar e não parou, teve gente que caiu e ninguém fez nada. Ah, a Lu tava até agora falando que caiu, né Lu? Caiu e ninguém falou nada. Aí o Albino falou assim que era o time dela que estava com a bola".

Rapidamente, a aluna Lu respondeu para sua colega Mili:

Aluna Lu: "Mas independente, se eu pedi pra parar, parou".

E a aluna Mili questionou de volta a aluna Lu:

Aluna Mili: "Mas você pediu para parar?".

A aluna Lu respondeu que sim, e sua colega Mili falou como devolutiva:

Aluna Mili: "Então fala isso pro seu time" (III - 16).

Ainda nesses aspectos, é necessário que a "[...] sororidade também seja vista diante de várias perspectivas para que não caia em um igualitarismo utópico, ou mesmo, coloque as mulheres como seres somente do bem ou vítimas" (SILVA, 2016, p. 51).

Quando a aluna Lu foi responder ao prof. Tiago, a aluna Fer interrompeu e disse:

Aluna Fer: "Ah, tinha pouca gente né? E essa aula quase deu briga". Finalmente, a aluna Lu conseguiu se expressar:

Aluna Lu: "Mas o respeito à pessoa não dá a hora que tipo, tem pouca gente tem mais gente, ela dá toda hora".

A aluna Fer respondeu para a aluna Lu:

Aluna Fer: "Depende da pessoa".

Logo em seguida, outra aluna, a Gabizela, falou para a aluna Fer:

Aluna Gabizela: "Mas é a regra o respeito Fer" (III - 27).

É possível perceber que essa categoria permite expor a relação entre as alunas diante do modelo igualitário proposto pelo Fútbol Callejero, no qual as meninas tomaram atitudes, desenvolveram diálogos e buscaram a resolução de possíveis conflitos na base do diálogo e dos três pilares que sustentam a prática do Fútbol Callejero: solidariedade, respeito e cooperação.

\section{C) “MAS SE EU PEDIR PRA PARAR, TEM QUE PARAR, ENTENDEU?"}

A terceira e última categoria emergiu mediante as posturas tomadas pelas meninas frente às atitudes dos meninos, ora de omissão:

O prof. Tiago foi até às alunas que se recusaram a participar da atividade e as questionou: 
Prof. Tiago: "Por que vocês não quiseram participar?".

Aluna Teltel: "Sou muito ruim professor e os meninos me xingam pois não aceitam que eu erre as jogadas".

As demais alunas concordaram com a fala de Teltel, acrescentando que não tinham afinidade com a bola nos pés e que os meninos eram competitivos (I 04d).

Ora de posicionamento: "De volta à sala de aula, o aluno Dhiogão conversou com a aluna Fer, perguntando se eles poderiam deixar o time certo para a próxima aula, mas ela se recusou" (I - 22).

Então, escolheu-se para o nome dessa categoria a fala de uma aluna que demonstra seu posicionamento perante um colega, em um contexto de $3^{\circ}$ tempo do Fútbol Callejero:

O aluno Albino, por sua vez, disse para a aluna Lu:

Aluno Albino: "Mas era seu time que tava com a bola".

E a aluna Lu respondeu de volta para o aluno Albino:

Aluna Lu: "Mas se eu pedir pra parar, tem que parar, entendeu?".

O aluno Albino finalizou, dizendo:

Aluno Albino: "Então fala pro seu time" (III - 13).

As mulheres sofrem as mais variadas violências, “[...] apenas mudando a forma, como e onde essa opressão acontece" (SILVA, 2016, p. 43). Devido a esse fato, o isolamento da mulher torna-se o "[...] modo mais fácil para que ela não possa se empoderar e enfrentar a dominação masculina" (SILVA, 2016, p. 13). As observações e anotações feitas para este estudo exibem que essa atitude ainda acontece no ambiente escolar, todavia, em menor escala: "O aluno K2 passou a aluna Má para o outro time sem pedir permissão a ela e a aluna Má também não contestou” (VI - 18d).

Outra ação que ainda está presente nesse ambiente é a reprodução de "[...] argumentos que reduzem à dimensão biológica a única razão de ser das diferenças de desempenho entre mulheres e homens" (BELMONTE; GONÇALVES JUNIOR; SOUZA JÚNIOR, 2018, p. 254):

[...] o grupo da questão $1{ }^{9}$ iniciou seus argumentos. A aluna Mari se levantou e começou seu discurso:

Aluna Mari: “A gente defende essa tese de que deve ser separado o esporte entre homens e mulheres porque mesmo que a mulher treinar nas mesmas condições e períodos que um homem, ela não vai conseguir se igualar a ele, pois a naturalidade da mulher é diferente do homem. O homem tem mais hormônio da testosterona e a mulher acaba sendo mais fraca que o homem por esse motivo, por exemplo, se pegar a Mi e o K1 para treinar o mesmo treino, com as mesmas condições, com a mesma alimentação, tudo da mesma forma, por mais que a Mi se esforce, o K1 vai se sair melhor no final de tudo isso" (V - 10d).

Mesmo com os meninos já compreendendo e defendendo que essa dimensão biológica é ultrapassada, "[...] este olhar simplista e reducionista foi, e ainda está, muito presente" (BELMONTE; GONÇALVES JUNIOR; SOUZA JÚNIOR, 2018, p. 254) nas falas de algumas alunas, decorrentes das "[...] estruturas de dominação estarem

\footnotetext{
${ }^{9}$ Atividade Júri Simulado: simulou-se um tribunal judiciário, com a sala dividida em três grupos, sendo 2 grupos debatedores e 1 grupo veredito. O processo de construção e desconstrução de gênero nos esportes (aula 4 - unidade didática) deu-se a partir das afirmações: Grupo questão 1: A separação entre esportes masculinos e femininos é necessária por diferenças físicas que afetam o desempenho; Grupo questão 2: Homens e mulheres poderiam praticar esportes de forma mista.
} 
profundamente arraigadas à sociedade, as mulheres também podem reproduzir discursos e ações que favorecem e legitimam a dominação masculina" (SILVA, 2016, p. 47): "Após a fala do aluno Decário, a aluna Mari pediu a palavra para rebater: por mais que os dois tenham o mesmo treino juntos, da mesma forma, a força física do homem vai ser maior, por isso ele vai se sair melhor nos esportes" (V - 11d).

No entanto, romper o silêncio é uma das premissas para que as meninas se tornem "[...] protagonistas no processo de transformação de suas realidades" (BELMONTE; GONÇALVES JUNIOR; SOUZA JÚNIOR, 2018, p. 265).

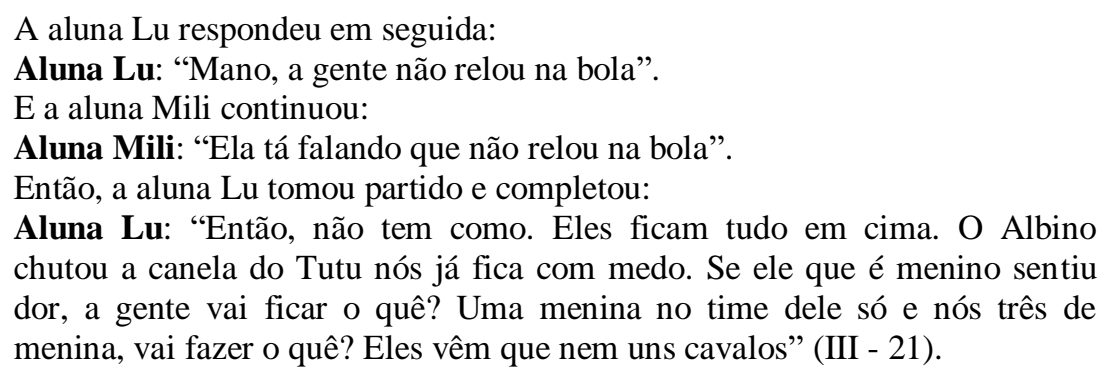

Assim como o movimento feminista é "[...] marcado pela disputa dos espaços de fala na tentativa de garantir uma narrativa histórica plural que contemple a visão de mundo das mulheres" (PINTO, 2016, p. 60), as condutas das meninas nas aulas de Educação Física Escolar também foram devidamente marcadas, tanto na relação educador-educandas: "Ao final da votação, o prof. Tiago estava concluindo que o gol tinha sido validado, quando a mediadora Giba falou: não, de qualquer jeito não valeu professor, ele não tocou para o Vitão" (IV - 26).

Quanto na relação educandas-educandos: “[...] o aluno K1 marcou outro gol para a equipe de colete azul e a aluna Leticia, do time sem colete, alegou que o aluno K1 não tinha cumprido uma das regras de novo" (IV - 21).

Finalizando, essa categoria expõe a atual dualidade nas atitudes das meninas frente às dos meninos. Contudo, acredita-se que essa seja uma manifestação deste período de transição em que estamos vivendo, no qual "Una de las principales características de la implicación ciudadana de estas mujeres es su capacidad de superar relaciones desiguales" (PUIGVERT; MUÑOZ, 2012, p. 24).

\section{CONSIDERAÇÕES FINAIS}

Na busca por analisar, compreender e descrever a participação de meninas durante essas aulas de Educação Física Escolar, nota-se que as alunas assumiram funções determinantes para o desenvolvimento da prática do Fútbol Callejero, desfrutando da liberdade de escolha em suas participações e da sororidade que as une - "Se ia ser melhor ficar olhando o jogo, prestando atenção em tudo, ou jogar" (categoria A) e "No outro jogo eu saí com a bola, agora começa você" (categoria B), respectivamente.

Adicionalmente, a interrogação-afirmação "Mas se eu pedir pra parar, tem que parar, entendeu?" (categoria C), surge para romper algumas reduções da participação das alunas frente às atitudes dos meninos. Por ser uma temática social cada vez mais emergente, o posicionamento crítico das meninas produziu debates, modificou situações e contribuiu para o processo de ensino e aprendizagem, sempre associados aos três pilares do Fútbol Callejero.

Assim, com base nos dados coletados em campo, considera-se que este estudo buscou reconstituir a realidade vivenciada e observada, utilizando-se da metodologia do 
Fútbol Callejero - e sua relação de gênero intrínseca - com o mesmo desígnio expresso por Simone de Beauvoir, conforme citado pela Revista Feminize: "[...] o objetivo não é que as mulheres tirem o poder das mãos dos homens, pois isso não mudaria nada. A questão é exatamente destruir essa noção de poder" (FEMINIZE, 2019, p. 3).

\section{REFERÊNCIAS}

ANDRADE, C. C.; HOLANDA, A. F. Apontamentos sobre pesquisa qualitativa e pesquisa empíricofenomenológica. Estudos de Psicologia, Campinas, v. 27, n. 2, p. 259-268, abr.-jun. 2010.

BELMONTE, M. M.; GONÇALVES JUNIOR, L.; SOUZA JÚNIOR; O. M. de. Fútbol callejero e educação das relações de gênero. In: SALDANHA, D. F.; GONZALEZ, R. H. (Orgs.). Projetos sociais para crianças e adolescentes. Juiz de Fora: Editora Garcia, 2018. p. 251-274.

BOGDAN, R.; BIKLEN, S. Notas de campo. In: BOGDAN, R.; BIKLEN, S. (Orgs.). Investigação qualitativa em educação, uma introdução à teoria e aos métodos. Porto: Porto Editora, 1994. p. 150175.

CAPPI, A. Apresentação. In: PETRELLI, R. Fenomenologia: teoria, método e prática. Goiânia: Ed. UCG, 2001. p. 7-8.

FEMINIZE. Ondas Feministas. Diagramação: Marina Dias. Orientação: Tabata Costa. Conteúdo: Renata Porcellis. 9 jan. 2019. Disponível em: https://issuu.com/marinadias8/docs/revista. Acesso em: 8 abr. 2020.

GODOY, A. S. Introdução à pesquisa qualitativa e suas possibilidades. Revista de Administração de Empresas, São Paulo, v. 35, n. 2, p. 57-63, mar./abr. 1995.

MARTINS, J.; BICUDO, M. A. V. Capítulo IX - a modalidade fenomenológica de conduzir pesquisa em psicologia. In: MARTINS, J.; BICUDO, M. A. V. (Org.). A pesquisa qualitativa em psicologia. 5. ed. São Paulo: Centauro, 2005, p. 91-110.

MINAYO, M. C. S.; GUERRIERO, I. C. Z. Reflexividade como éthos da pesquisa qualitativa. Ciência \& Saúde Coletiva, v. 19, n. 4, p. 1103-1112, 2014.

MORENO, R. L. R.; JORGE, M. S. B.; GARCIA, M. L. P. Fenomenologia - fenômeno situado: opção metodológica para investigar o humano na área da saúde. Escola Anna Nery Revista de Enfermagem, v. 8 , n. 3, p. 348-353, dez. 2004.

MOVIMIENTO DE FÚTBOL CALLEJERO. Organizaciones. Disponível em: http://movimientodefutbolcallejero.org/movimiento/organizaciones-participantes. Acesso em: $08 \mathrm{abr}$. 2020.

MOVIMIENTO DE FÚTBOL CALLEJERO. Carta de principios. Buenos Aires, feb. 2013. Disponível em: http://movimientodefutbolcallejero.org/movimiento/carta-\%20de-principios/. Acesso em: 08 abr. 2020.

PETRELLI, R. Fenomenologia: teoria, método e prática. Goiânia: Ed. UCG, 2001.

PINTO, C. T. Feminismo 2.0: a nova dinâmica dos movimentos sociais na internet. 2016.75 f. Trabalho de Conclusão de Curso (Graduação em Comunicação Social) - Universidade Federal do Rio de Janeiro, Rio de Janeiro, 2016.

PUIGVERT, L.; MUÑOZ, B. Estudios de género. Barreras y aportaciones al debate teórico internacional desde las voces de las otras mujeres. Multidisciplinary Journal of Gender Studies, v. 1, n. 1, p. 4-27. 
ROSSINI, L; SERRANI, E; WEIBEL, M; WAINFELD, M. Fútbol Callejero: juventud, liderazgo y participación: trayectorias juveniles en organizaciones sociales de América Latina.Buenos Aires: G1 S.A., 2012.

SILVA, I. C. S. Sororidade e rivalidade feminina nos filmes de princesa da Disney. 2016. $130 \mathrm{f}$. Trabalho de Conclusão de Curso (Graduação em Jornalismo) - Universidade de Brasília, Brasília, 2016.

Silva GUTIERREZ, C. A.; DOTTO, A.; ALlET, A. Futebol Callejero, juventude e cidadania. Lúdica Pedagógica, v. 23, p. 19-29, 2016.

SOUZA, B. Vamos juntas? O guia da sororidade para todas. Rio de Janeiro: Galeria Record, 2016.

SOUZA JÚNIOR, O. M.; MARTINS, M. Z.; BELMONTE, M. M. Fútbol Callejero: desafios e potencialidades de uma metodologia para a Educação Popular. In: CONGRESSO INTERNACIONAL DE EDUCAÇÃO FÍSICA E MOTRICIDADE HUMANA/XV SIMPÓSIO PAULISTA DE EDUCAÇÃO FÍSICA, 9./15., 2015, Rio Claro. Anais [...]. Rio Claro: Motriz, Suplemento, v.21, 2015. p. S228-S228.

VAROTTO, N. R.; GONÇALVES JUNIOR, L.; LEMOS, F. R. M. "Fútbol Callejero": processos educativos emergentes da prática social da mediação. Revista Kinesis, Santa Maria, v. 35, n. 3, p. 91100, set.-dez. 2017.

VAROTTO, N. R.; GONÇALVES JUNIOR, L.; LEMOS, F. R. M.; MORAES, F. "Fútbol Callejero" na Educação Física Escolar: processos educativos emergentes de uma intervenção. Revista Brasileira de Iniciação Científica, Itapetininga, v. 5, n. 5, p. 104-120, out./dez., 2018.

Recebido em: 08 abr. 2020.

Aprovado em: 25 abr. 2020. 